Jurnal Kejaora: Jurnal Kesehatan Jasmani dan Olah Raga

ISSN: 2541-5042 (Online)

ISSN: 2503-2976 (Print)

Volume 5 Nomor 1, Edisi April 2020

\title{
PERBANDINGAN LATIHAN FOOTWORK DAN SHADOW TERHADAP KELINCAHAN ATLET TIM BULUTANGKIS PB. SETIA PUTRA
}

\author{
Achmad Rifai ${ }^{1}$, Domi Bustomi², Sumbara Hambali ${ }^{3}$ \\ 1,2Universitas Islam 45 Bekasi \\ 3STKIP Pasundan \\ Email:achmad_rifai13@yahoo.com¹, dbustomi01@gmail.com², ,sumbarahambali8@gmail.com³ \\ DOI: https://doi.org/10.36526/kejaora.v5i1.848
}

\begin{abstract}
ABSTRAK
Kelincahan merupakan komponen fisik yang sangat penting dalam olahraga bulutangkis, hal ini dikarenkan agar para pemain dapat bergerak ke segala arah dengan cepat dan tepat untuk mengejar ataupun megembalikan shuttlecock ke daerah lapangan lawan. Penelitian ini bertujuan untuk mengetahui pengaruh dari latihan footwork dan latihan shadow terhadap kelincahan atlet tim bulutangkis PB. Setia Putra. Metode penelitian yang digunakan adalah eksperimen dengan menggunakan pretest-postest design. Populasi dalam penelitian ini adalah seluruh atlet tim bulutangkis PB. Setia Putra, dengan menggunakan teknik sampling yaitu total sampling. Maka sampel dalam penelitian ini adalah seluruh atlet bulutangkis PB. Setia Putra sebanyak 20 orang. Instrumen yang digunakan dalam mengumpulkan data adalah tes kelincahan dengan boomerang run. Hasil penelitian berkesimpulan bahwa: (1) Terdapat pengaruh yang signifikan latihan footwork terhadap kelincahan atlet bulutangkis PB. Setia Putra, karena nilai thitung $>t_{\text {tabel }}(12,67>2,10),(2)$ Terdapat pengaruh yang signifikan latihan shadow terhadap kelincahan atlet bulutangkis PB. Setia Putra, karena nilai $t_{\text {hitung }}>t_{\text {tabel }}(14,84>2,10)$, (3) Latihan shadow memberikan pengaruh lebih signifikan terhadap kelincahan atlet bulutangkis dari pada latihan footwork. Bagi para pelatih, pembina, dan juga atlet agar dapat menerapkan prinsip-prinsip latihan dalam latihan fisiknya, khususnya jika ingin meningkatkan kelincahan dapat menggunakan bentuk latihan shadow. Khususnya bagi para peneliti yang hendak meneliti dengan variabel yang sama, dapat mencoba untuk membandingkan dengan bentuk latihan yang lain.
\end{abstract}

Kata Kunci: Latihan Footwork, Shadow, Atlet dan Bulutangkis

\section{PENDAHULUAN}

Bulutangkis merupakan salah satu cabang olahraga yang sangat populer di Indonesia. Olahraga ini juga sangat digemari oleh masyarakat disemua kalangan, mulai dari tua sampai muda, laki-laki dan peremupuan. Hal ini dapat tercermin dari banyaknya klub-klub mulai dari level daerah sampai nasional. Disamping itu, dapat dilihat dari antusiasnya masayarakat disetiap ada pertandingan bulutangkis. Oleh karena itu, PBSI sebagai induk organisasi bulutangkis melakukan pembinaan besar-besaran (Rahman \& Warni, 2017). Bulutangkis adalah salah satu cabang olahraga yang permainannya adalah memukul shuttlecock dengan menggunakan raket setepat mungkin ke daerah lawan.
Permainan bukutangkis merupakan jenis permainan yang memerlukan kecepatan dan kelincahan yang baik untuk memukul shuttlecock, dimana teknik langkah kaki atau footwork dan pukulan atau stroke yang benar akan menghasilkan pukulan yang sempurna (Hamid \& Aminuddin, 2019). Bulutangkis dianggap sebagai salah satu olahraga, dimana teknik gerak kaki menjadi sangat penting diantara keterampilan lainnya, dan pukulan forehand dianggap sebagai teknik yang paling kuat (Yousif \& Yeh, 2011). Tujuan permainannya adalah untuk mengirimkan shuttlecock melewati net sehingga masuk ke lapangan lawan (Yousif \& Yeh, 2011). Tentunya menjadi seorang pemain bulutangkis yang hebat bukan merupakan pekerjaan yang mudah, karena membutuhkan pemahaman dan penguasaan 
Jurnal Kejaora: Jurnal Kesehatan Jasmani dan Olah Raga

ISSN: 2541-5042 (Online)

ISSN: 2503-2976 (Print)

Volume 5 Nomor 1, Edisi April 2020

berbagai keterampilan fisik, teknik, taktik dan juga psikologis secara simultan agar menghasilkan permainan yang efektif dan efisien (Putra, Ramadi, Putu, \& Wijayanti, 2017). Setidaknya ada lima faktor penentu dalam meraih prestasi atlet, yaitu: kepribadian atlet, kondisi fisik, keterampilan teknik, keterampilan taktis dan kemampuan mental (Tangkudung \& Puspitorini, 2012). Pada saat kita mengamati pertandingan bulutangkis, biasanya para atlet membutuhkan sejumlah kekuatan, kecepatan, kelincahan, daya tahan dam juga koordinasi yang baik (Jaworski \& Zak, 2015). Dilihat dari karakteristik permainannya, bulutangkis merupakan olahraga yang pergerakan permainannya sangat cepat. Para pemain bulutangkis harus mampu melakukan gerakan-gerakan seperti sprint, meloncat, menjangkau, memutar badan, melangkah lebar, dan mencoba menanggapi serangan lawan dengan cepat dan tepat (Kusuma, 2013). Dan salah satu komponen kondisi fisik yang paling harus dikuasai oleh pemain bulutangkis adalah kelincahan.

Kelincahan adalah kemampuan atlet untuk mengubah arah posisi tubuhnya secara cepat dan dilakukan bersamaan dengan gerakan lainnya (Widiastuti, 2015). Literatur lain menunjukan bahwa kelincahan harus mempertimbangkan tidak hanya kecepatan, tetapi kemampuan untuk mengurangi kecepatan, mengubah arah, dan memperbaharui kembali dalam menaggapi rangsangan (Bompa \& Buzzichelli, 2015). Dengan memiliki kelincahan yang baik, atlet akan mampu bertindak cepat dalam menghadapi rangsangan, dalam hal ini serangan dari lawan.

Maka dari itu, perlu kiranya kelincahan seorang atlet dilatih agar dapat menampilkan performa yang maksimal. Kelincahan pada cabang olahraga bulutangkis berguna untuk para pemain agar dapat bergerak cepat ke berbagai arah, baik untuk mengejar atau mempertahankan shuttlecock agar tidak jatuh di daerah lapangan sendiri, maupun untuk mebalas penyerangan. Kebutuhan dalam proses pelatihan pemain bulutangkis dapat dihubungkan oleh dua faktor, yaitu pelatihan tujuan khusus dan pelatihan komprehensif,

hal ini agar pelatihan tidak monoton (Karatnyk, Hrechanyuk, Bubela, \& Pityn, 2016). Berbagai bentuk latihan kelincahan pernah dilakukan oleh beberapa peneliti, diantaranya adalah dengan latihan footwork dan latihan shadow. Latihan footwork merupakan bentuk latihan gerakan langkah kaki untuk dapat mengatur badan agar mudah dalam memukul shuttlecock (Fawzi \& Jayadi, 2018). Sedangkan latihan shadow merupakan bentuk latihan yang mengharuskan atlet untuk melakukan gerakan ke berbagai sudut lapang permainan, sehingga atlet akan terbiasa melakukan gerakan tersebut dalam permainannya (Sukesih, 2015).

Dari beberapa penelitian juga disebutkan bahwa kedua bentuk latihan tersebut memiliki pengaruh terhadap kelincahan. Beberapa diantaranya yaitu menyebutkan bahwa terdapat pengaruh latihan footwork terhadap kelincahan pada atlet putra U-15 bulutangkis Mandiri Pekanbaru, dan latihan shadow juga memliki pengaruh terhadap peningkatan kelincahan para peserta ekstrkurikuler bulutangkis di SMAN 4 Singaraja (Kusuma, 2013; Putra et al., 2017).

Berdasarkan hal tersebut penulis tertarik untuk meneliti tentang kedua bentuk latihan tersebut, yang dimana tujuan penelitian ini adalah untuk mengetahui manakah yang memiliki pengaruh lebih besar antara latihan footwork dan latihan shadow terhadap peningkatan kelincahan para atlet bulutangkis PB. Setia Putra Karawang.

\section{METODE}

Metode penelitian yang digunakan adalah eksperimen. Metode ini digunakan dalam rangka mengadakan percobaan untuk melihat suatu hasil, dimana hasil tersebut dapat menegaskan bagaimana hubungan kausal antar variabel yang sedang diselidiki (Arikunto, 2012). Desain penelitian yang digunakan adalah pretest-posttest design, berikut gambar desain penelitiannya:

\begin{tabular}{|lllll|}
\hline $\mathrm{O}_{1}$ & - & $\mathrm{X}_{1}$ & - & $\mathrm{O}_{2}$ \\
$\mathrm{O}_{3}$ & - & $\mathrm{X}_{2}$ & - & $\mathrm{O}_{4}$ \\
\hline
\end{tabular}

Gambar 1. Desain Penelitian 
Jurnal Kejaora: Jurnal Kesehatan Jasmani dan Olah Raga

ISSN: 2541-5042 (Online)

ISSN: 2503-2976 (Print)

Volume 5 Nomor 1, Edisi April 2020

Keterangan:

01 : Pretest Kelompok A (Latihan Footwork)

X1 : Latihan Footwork

O2 : Posttest Kelompok A (Latihan Footwork)

O3 : Pretest Kelompok B (Latihan Shadow

X2 : Latihan Shadow

O4 : Posttest Kelompok B (Latihan Shadow)

Populasi dalam penelitian ini adalah seluruh atlet bulutangkis PB. Setia Putra Karawang yang berjumlah 20 orang. Sampel dalam penelitiannya adalah seluruh populasi atau teknik total sampling. Dimana dari 20 orang tersebut akan dibagi menjadi dua kelompok, yaitu kelompok A sebanyak 10 orang diberikan latihan footwork, dan kelompok B 10 orang diberikan latihan shadow. Pada latihan footwork para peserta diberikan bentuk latihan seperti memindahkan shuttlecock dari satu tempat ke tempat yang lain pada lapangan sendiri dan juga menggunakan instruktur sebagai pengarah dimana atlet harus bergerak mengambil shuttlecock yang diarahkan oleh pelatih/instruktur. Sedangkan untuk latihan shadow para pemain membayangkan ada dalam situasi pertandingan sesungguhnya, dimana penempatan shuttlecock dari lawan sudah ditentukan sebelumnya oleh pelatih. Semua latihan dilakukan sebanyak 3 set dengan masing-masing set sebanyak 10 repetisi. Penelitian dilakukan pada Bulan Juli 2019 di lapangan bulutangkis PB. Setia Putra Karawang.

Instrumen yang digunakan untuk mengukur kelincahan dalam penelitian ini adalah tes boomerang run. Teknik analisis data menggunakan pendekatan statistika. Dengan prosedur sebagai berikut: 1) Mencari nilai mean dan standar deviasi pada masingmasing periode tes, 2) Melakukan pengujian persyaratan analisis, meliputi uji normalitas dan homogenitas, 3) Melakukan uji hipotesis pada masing-masing kelompok.

\section{HASIL DAN PEMBAHASAN}

Pengolahan dan analisis data dilakukan setelah peneliti memberikan

perlakuan atau treatment kepada dua kelompok berupa latihan footwork pada kelompok A dan latihan shadow pada kelompok B. Ini adalah beberapa dokumentasi yang dapat ditampilkan pada gambar 2 berikut ini:

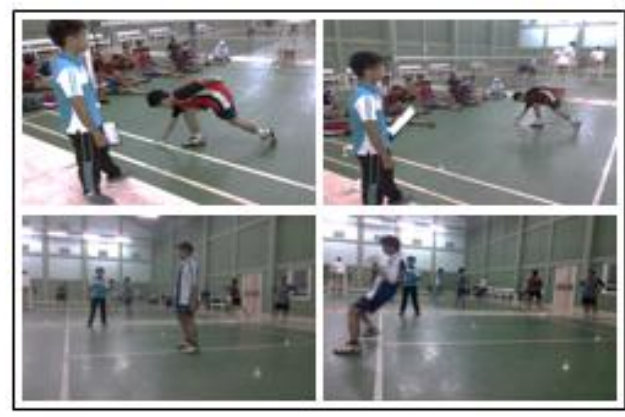

Gambar 2. Dokumentasi Penelitian

Berdasarkan hasil pengolahan dan analisis data yang telah dilakukan, maka didapat hasil skor mean dan standar deviasi berikut ini:

\begin{tabular}{cccc}
\multicolumn{4}{c}{ Tabel 1. Data Hasil Tes Kelincahan } \\
\hline Kelompok & Tes & Mean & $\begin{array}{c}\text { Std. } \\
\text { Deviasi }\end{array}$ \\
\hline A & Awal & 0.45 & 2.09 \\
\cline { 2 - 4 } & Akhir & 0.15 & 2.06 \\
\hline \multirow{2}{*}{ B } & Awal & 0.30 & 1.75 \\
\cline { 2 - 4 } & Akhir & 0.20 & 2.53 \\
\hline
\end{tabular}

Dari data tabel 1 di atas, dapat diketahui bahwa nilai rata-rata pretest pada kelompok A sebesar 0,45 dan standar deviasinya sebesar 2,09, sedangkan pada kelompok $\mathrm{B}$ didapat nilai rata-rata pretest sebesar 0,30 dan standar deviasinya sebesar 1,75 .

Setelah hasil skor rata-rata dan simpangan baku didapat, maka selanjutnya melakukan uji normalitas menggunakan liliefors. Hasil perhitungan pengujiannya dapat dilihat pada tabel 2 berikut ini:

Tabel 2. Hasil Pengujian Normalitas

\begin{tabular}{ccccc}
\hline Kelompok & Tes & L hitung & L tabel & Hasil \\
\hline \multirow{2}{*}{ A } & Awal & 0.178 & 0.190 & \multirow{2}{*}{ Normal } \\
\cline { 2 - 4 } & Akhir & 0.180 & 0.190 & \\
\hline \multirow{2}{*}{ B } & Awal & 0.185 & 0.190 & \multirow{2}{*}{ Normal } \\
\cline { 2 - 4 } & Akhir & 0.188 & 0.190 & \\
\hline
\end{tabular}

Berdasarkan tabel 2 tersebut, dapat dilihat bahwa nilai Lhitung pada setiap kelompok dan setiap tes menunjukan skor lebih kecil 
Jurnal Kejaora: Jurnal Kesehatan Jasmani dan Olah Raga

ISSN: 2541-5042 (Online)

ISSN: 2503-2976 (Print)

Volume 5 Nomor 1, Edisi April 2020

dari Ltabel. Ini artinya bahwa data tersebut berdistribusi normal.

Setelah uji normalitas, selanjutnya melakukan uji homogenitas dengan kesamaan dua varians. Hasil pengujiannya dapat dilihat pada tabel 3 berikut ini:

Tabel 3. Hasil Pengujian Homogenitas

\begin{tabular}{ccccc}
\hline Kelompok & Tes & $\boldsymbol{F}_{\text {hitung }}$ & $\boldsymbol{F}_{\text {tabel }}$ & Hasil \\
\hline \multirow{2}{*}{ A \& B } & Awal & 1.43 & \multirow{2}{*}{4.35} & Homogen \\
\cline { 2 - 3 } & Akhir & 1.51 & & \\
\hline
\end{tabular}

Atas dasar hasil pengujian kesamaan dua variasi di atas, diketahui bahwa hasil $F_{\text {hitung }}$ tes awal $=1,43$ dan $F_{\text {nitung }}$ tes akhir $=$ 1,51 yang lebih kecil dari $F_{\text {tabel }}=4,35$ pada dk $=(9,9)$ dengan taraf singnifikansi $a=0,05$. Kesimpulan dari hasil pengujian kesamaan dua variasi adalah kedua kelompok homogen.

Setelah data berdistribusi normal dan kedua kelompok homogen, selanjutnya dilakukan pengujian hipotesis pada masingmasing kelompok. Hasil pengujian hipotesis pada masing-masing kelompok dapat dilihat pada tabel 4 berikut ini:

Tabel 4. Hasil Pengujian Hipotesis

\begin{tabular}{cccc}
\hline Kelompok & $\mathbf{t}_{\text {hitung }}$ & $\begin{array}{c}\mathbf{t}_{\text {tabel }} \\
(\mathbf{0 . 9 7 5 : 1 8 )}\end{array}$ & Hasil \\
\hline A & 0.228 & 0.127 & Signifikan \\
\hline B & 0.247 & 0.127 & Signifikan \\
\hline
\end{tabular}

Penghitungan dan uji signifikansi peningkatan dari hasil latihan kedua kelompok dilakukan dengan menggunakan uji signifikansi yaitu uji $t$, dari hasil pengujian tersebut diperoleh bahwa thitung pada kelompok latihan footwork $=0,228$, lebih besar dari tabel pada tingkat kepercayaan atau taraf signifikansi $\alpha=0.005$ dengan $\mathrm{dk}\left(\mathrm{n}_{1}+\mathrm{n}_{2}\right.$ $-2)=18$, harga $t(0.975)$ yaitu 0,127 . kriteria pengujian adalah, terima Ho jika $-t_{1-1 / 2 a}<t<t$ 1-1/2a. Maka $t$ hitung berada pada daerah penolakan $\mathrm{H}_{0}$, jadi $\mathrm{H}_{0}$ ditolak. Kesimpulannya adalah latihan footwork memberikan pengaruh yang signifikan terhadap peningkatan kelincahan atlet bulutangkis PB. Setia Putra.

Sedangkan dari hasil pengujian kedua diperoleh thitung pada latihan shadow $=0,247$ lebih besar dari ttabel pada tingkat

kepercayaan atau taraf signifikansi $\alpha=0,05$ dengan $\mathrm{dk}\left(\mathrm{n}_{1}+\mathrm{n}_{2}-2\right)=18$, harga $\mathrm{t}(0,975)$ yaitu 0,127 . kriteria pengujian adalah, terima

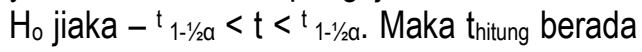
pada daerah penolakan $\mathrm{H}_{0}$, jadi $\mathrm{H}_{0}$ ditolak. Kesimpulannya adalah latihan shadow memberikan pengaruh yang signifikan terhadap peningkatan kelincahan atlet bulutangkis PB. Setia Putra..

Di lihat dari tes akhir kedua kelompok, maka dapat di simpulkan bahwa kelompok latihan shadow lebih signifikan dibanding kelompok latihan footwork, karena t hitung yang diperoleh kelompok latihan shadow yaitu 0,247 lebih lebih besar dibandingkan $t$ hitung yang diperoleh kelompok latihan footwork yaitu 0,228.

Dari hasil penelitian yang telah dipaparkan, didapat keterangan bahwa latihan footwork maupun latihan shadow sama-sama memberikan pengaruh yang signifikan. Kesesuian dari latihan footwork dengan tuntutan konsep kelincahan yaitu pada perubahan arah secara tiba-tiba pada saat bergerak dengan cepat tanpa kehilangan keseimbangan. Semakin baik atlet bulutangkis menguasai langkah kaki (footwork) dengan kelincahan, maka semakin baik dalam mengantisipasi shuttlecock yang datang (I Putu Astrawan, Adiputra, \& Jawi, 2016). Dengan latihan footwork pemain juga dapat sampai di titik penerimaan bola dengan lebih cepat, sehingga mampu mengatur pengembalian shuttlecock, seberapa besar kekuatan yang dikeluarkan, dan melihat mana tempat yang kosong (Ramadhan, Subarkah, \& Wardoyo, 2018). Latihan footwork ini sangat tepat dan sesuai dengan kebutuhan atlet bulutangkis dalam meningkatkan kelincahan gerakan kaki atlet (Putra et al., 2017). Setiap pemain ketika ingin melakukan pukulan, mereka harus mengejar shuttlecock dengan langkah kaki yang ringan dan lincah ke semua sudut lapangan permainan (Hamid \& Aminuddin, 2019). Semakin baik kualitas fisik atlet, maka penampilannya semakin bagus. Karena untuk menjadi pemain bulutangkis yang berprestasi seorang atlet harus menguasai teknik dasar pendukung seperti teknik, fisik, taktik dan mental (Nandika, Hadi, \& Ridho, 2017). Dan beberapa komponen kondisi fisik yang 
Jurnal Kejaora: Jurnal Kesehatan Jasmani dan Olah Raga

ISSN: 2541-5042 (Online)

ISSN: 2503-2976 (Print)

Volume 5 Nomor 1, Edisi April 2020

berpengaruh terhadap keterampilan atlet adalah keterampilan, kekuatan, kelentukan, daya tahan, kecepatan, kelincahan, dan koordinasi (Hambali \& Sobarna, 2019). Maka dari itu, kiranya latihan footwork ini dapat dijadikan sebagai latihan untuk meningkatkan unsur fisik juga, salah satunya adalah kelincahan.

Sedangkan pada latihan shadow tuntutan gerakan juga sesuai dengan kriteria permainan bulutangkis yang membutuhkan gerak yang cepat secara dinamis, bergerak maju mundur dengan cepat dan tepat. Pada latihan shadow ini pemain harus mengambil dan meletakan shuttlecock ke tepi lapangan, dan bergerak meniru gerakan bayangan enam sudut lapang bulutangkis (Muthiarani, 2017). Kelincahan tidak begitu saja terbentuk dengan sendirinya, perlu kiranya suatu bentuk latihan agar kelincahan dapat meningkat, dan salah satunya bisa dengan latihan shadow (Saputra \& Sepdanius, 2019). Penelitian lain juga menyatakan bahwa terdapat pengaruh latihan shadow terhadap peningkatan kelincahan dalam permainan bulutangkis (Firmana, 2017). Dalam hal ini shadow maksudnya banyangan, jadi yang maksud dari latihan shadow pada bulutangkis adalah suatu bentuk latihan yang dilakukan dengan membayangkan berada dalam suatu permainan, dan ini membuktikan bahwa latihan seperti ini mampu meingkatkan agility para pemain bulutangkis (Rahman \& Warni, 2017).

Dalam permainan bulutangkis, bentuk latihan shadow merupakan salah satu bentuk latihan yang diperlukan dalam permainan sebagai upaya meningkatkan kelincahan. Bentuk latihan shadow menuntut atlet untuk bergerak ke segala arah. Proses gerak ini sesuai dengan gerakan sebenarnya dalam permainan bulutangkis yang juga tidak terlepas dari gerakan sebenarnya dalam permainan bulutangkis yang juga tidak terlepas dari gerak ke segala arah, misalnya setelah melakukan serangan atau smash pemain cepat kembali ke posisi untuk siap melakukan pola pertahanan, yang mana tujuannya untuk terus fokus melihat atau membaca pergerakan lawan dan bola sehingga setiap pemain selalu siap untuk mengantisifasi shuttlecock yang akan

dikembalikan ke daerahnya sendiri. Ini tentunya membutuhkan tingkat agilitas yang tinggi, dan latihan shadow cocok dengan karakteristik seperti itu. Bentuk-bentuk latihan untuk mengembangkan agilitas adalah bentuk-betuk latihan yang mengharuskan orang untuk bergerak dengan cepat dan mengubah arah dengan tangkas, tidak boleh kehilangan keseimbangan dan sadar akan posisi dirinya (Harsono, 2017).

Dalam hal ini latihan footwork dan latihan shadow telah memenuhi kriteria latihan untuk meningkatkan kelincahan pemain bulutangkis sehingga memberikan pengaruh yang signifikan terhadap kelincahan atlet bulutangkis. Setelah dilakukan uji signifikansi perbedaan peningktan hasil latihan menujukkan bahwa latihan shadow memberikan pengaruh yang lebih baik dibandingkan latihan footwork terhadap kelincahan atlet bulutangkis. Perbedaan peningkatan hasil latihan tersebut disebabkan pelaksanaan latihan shadow badminton lebih sesuai dengan tuntutan gerak dan kriteria kelincahan yaitu bergerak dengan cepat saat terjadi perubahan arah gerak. Kunci untuk meningkatkan kelincahan adalah dengan meminimalisir pengurangan kecepatan ketika terjadu perubahan titik berat badan (Brown \& Ferrigno, 2015). Dalam hal ini, tingkat pengurangan kecepatan gerak saat konstan dengan badan selalu menhadap ke depan. Berbeda dengan latihan footwork yang menuntut sampel untuk melakukan lari bolak-balik ke arah yang sama, sehingga saat mencapai batas harus berhenti dan berbalik arah lari. Oleh karena itu kecepatan gerak lari dan keseimbangan badan menjadi berkurang.

\section{KESIMPULAN}

Berdasarkan hasil penelitian dan pembahasan yang telah dipaparkan sebelumnya, maka penelitian ini dapat menyimpulkan bahwa: 1) Latihan footwork memberikan pengaruh yang signifikan terhadap kelaincahan atlet bulutangkis PB. Setia Putra Karawang, 2) Latihan shadow memberikan pengaruh yang signifikan terhadap kelaincahan atlet bulutangkis PB. Setia Putra Karawang, 3) Latihan shadow memberikan pengaruh lebih besar terhadap 
Jurnal Kejaora: Jurnal Kesehatan Jasmani dan Olah Raga

ISSN: 2541-5042 (Online)

ISSN: 2503-2976 (Print)

Volume 5 Nomor 1, Edisi April 2020

kelincahan daripada latihan footwork pada atlet bulutangkis PB. Setia Putra Karawang. Saran penulis terhadap para pelatih, pembina ataupun atlet hendaknya dapat menerapkan prinsip-prinsip latihan yang baik, agar target program latihan dapat tercapai secara maksimal. Kemudian diharapkan kedua bentuk latihan tersebut lebih ditingkatkan, dengan menggunakan sarana latihan yang lebih efektif dan efisien, baik dalam segi pelaksanaan latihan maupun pemahaman tujuan dari latihan tersebut, sehingga menyadari arti pentingnya tujuan dari latihan shadow badminton footwork.

\section{DAFTAR PUSTAKA}

Arikunto, S. (2012). Prosedur Penelitian Suatu Pendekatan Praktek. Jakarta: Rineka Cipta.

Bompa, T. O., \& Buzzichelli, C. (2015). Periodization Training for Sports (Third Edit). Retrieved from http://93.174.95.29/_ads/5722859374 FD7062327E8B2E6C8F1177

Brown, L. E., \& Ferrigno, V. A. (2015). Training For Speed, Agility \& Quickness. USA: Human Kinetics.

Fawzi, O. S., \& Jayadi, I. (2018). Pengaruh Latihan Footwork Terhadap Tinggi Lompatan, Kecepatan, Dan Kelincahan Pada Pemain Bulutangkis (Studi Pada Ekstrakulikuler Sman 13 Surabaya). Jurnal Prestasi Olahraga, 3(1), 1-7. Retrieved from https://jurnalmahasiswa.unesa.ac.id/i ndex.php/jurnal-prestasiolahraga/article/view/23030

Firmana, I. (2017). Pengaruh Latihan Shadow Terhadap Peningkatan Kelincahan Dalam Permainan Bulutangkis. Educator, 3(1). Retrieved from http://jurnal.upmk.ac.id/index.php/edu cater/article/view/67/52

Hambali, S., \& Sobarna, A. (2019). Keterampilan Smash Bolavoli (Studi Korelasi Antara Power Lengan, Koordinasi Mata Tangan dan Percaya Diri Pada atlet Club Osas Kabupaten Sumedang). Jurnal Olympia, 1(2).

Hamid, A., \& Aminuddin, M. (2019). Pengaruh Latihan Footwork Terhadap Agility Pada Pemain Bulutangkis Pbsi Tanah

Laut Usia 12-15. Multilateral Jurnal Pendidikan Jasmani Dan Olahraga, 18(1), $\quad$ 51-55. https://doi.org/10.20527/multilateral.v $18 \mathrm{i} 1.6568$

Harsono. (2017). Kepelatihan Olahraga: Teori dan Metodologi. Bandung: Rosdakarya.

I Putu Astrawan, Adiputra, N., \& Jawi, I. M. (2016). Pelatihan Footwork Bulutangkis 10 Repetisi 2 Set Lebih Baik Dibandingkan 5 Repetisi 4 Set Untuk Meningkatkan Kekuatan Otot Tungkai Dan Kelincahan. Sport and Fitness Journal, 4(2), 18-29. Retrieved from https://ojs.unud.ac.id/index.php/sport/ article/download/24035/15692

Jaworski, J., \& Zak, M. (2015). The Structure of Morpho-Functional Conditions Determining the Level of Sports Performance of Young Badminton Players. Journal of Human Kinetics, 47(1), 215-223. https://doi.org/10.1515/hukin-20150077

Karatnyk, I. V., Hrechanyuk, O. O., Bubela, O. Y., \& Pityn, M. P. (2016). Perfection of badminton players' speed-power fitness with the help of training means' variable modules. Pedagogics, Psychology, Medical-Biological Problems of Physical Training and Sports, 20(03), 18-24. https://doi.org/10.15561/18189172.20 16.0303

Kusuma, G. N. A. (2013). Pengaruh Pelatihan Bayangan (Shadow) Bulutangkis Terhadap Peningkatan Kelincahan Dan Kecepatan Reaksi. Jurnal IImu Keolahragaan Undiksha, 1(1), 1-8. Retrieved from https://ejournal.undiksha.ac.id/index.p $\mathrm{hp} / J J / K /$ article/view/1571

Muthiarani, A. (2017). Pengaruh Latihan Shadow Menggunakan Langkah Berurutan Dan Langkah Bersilangan Terhadap Kelincahan Footwork Atlet Bulutangkis $\mathrm{Pb}$. Wiratama Jaya Yogyakarta. Jurnal Pend. Kepelatihan Olahraga - S1, 6(3), 1-9. Retrieved from 
Jurnal Kejaora: Jurnal Kesehatan Jasmani dan Olah Raga

ISSN: 2541-5042 (Online)

ISSN: 2503-2976 (Print)

Volume 5 Nomor 1, Edisi April 2020

http://journal.student.uny.ac.id/ojs/ind ex.php/pko/article/view/7588/7228

Nandika, R., Hadi, D. T., \& Ridho, Z. A. (2017). Pengembangan Model Latihan Strokes Bulutangkis Berbasis Footwork Untuk Anak Usia Pemula (U15). Gladi Jurnal IImu Keolahragaan, 8(2), 102-110. https://doi.org/10.21009/gjik.082.03

Putra, A. K., Ramadi, Putu, N., \& Wijayanti, N. (2017). The Effect of Footwork for Agility At Men Athlete of Persatuan Bulutangkis Mandiri Pekanbaru U-15. Jurnal Online Mahasiswa, 4(1), 1-8. Retrieved from https://jom.unri.ac.id/index.php/JOMF KIP/article/view/14108/13667

Rahman, T., \& Warni, H. (2017). Pengaruh Latihan Shadow 8 Terhadap Agility Pada Pemain Bulutangkis $\mathrm{Pb}$. Mustika Banjarbaru Usia 12 - 15 Tahun. Multilateral Jurnal Pendidikan Jasmani Dan Olahraga, 16(1), 16-24. https://doi.org/10.20527/multilateral.v $16 \mathrm{i} 1.3660$

Ramadhan, R., Subarkah, A., \& Wardoyo, H. (2018). Pengembangan Model Latihan Footwork Cabang Olahraga Bulutangkis. Jurnal IImiah Sport Coaching And Education Vol. 2 Juli 2018, 2(Juli), 150-158. Retrieved from http://journal.unj.ac.id/unj/index.php/js ce/article/download/9059/6080

Saputra, T. W., \& Sepdanius, E. (2019). Pengaruh Latihan Shadow Terhadap Peningkatan Kelincahan Atlet Bulutangkis $\mathrm{Pb}$. Lima Puluh Kota. Jurnal Stamina, 2(3), 171-177. Retrieved from http://stamina.ppj.unp.ac.id/index.php/ JST/article/view/364/169

Sukesih. (2015). Penerapan Latihan Shadow Dalam Upaya Meningkatkan Kelincahan Pada Materi Permainan Bulutangkis. Dinamika Jurnal IImiah Pendidikan Dasar, 7(1). Retrieved from http://jurnalnasional.ump.ac.id/index.p hp/Dinamika/article/view/921/860

Tangkudung, J., \& Puspitorini, W. (2012). Kepelatihan Olahraga: Pembinaan 